\title{
EDUCACIÓN Y TRABAJO: ¿UN BINOMIO QUE SUSCITA IDEAS PARA SER LIBRES Y DIGNOS DE VERDAD!
}

\section{EDUCATION AND WORK: A BINOMIO THAT MAKES IDEAS TO BE FREE AND WORTHY OF TRUTH!}

Enrique M. Jaramillo García*

\begin{abstract}
"Puede que el conocimiento nos haga poderosos, pero alcanzamos la plenitud a través de la comprensión [...]. Sin embargo, encontramos que esta educación en la comprensión no sólo es sistemáticamente ignorada en las escuelas, sino severamente reprimida.
\end{abstract}

Rabindranath Tagore, Mi escuela, 1916

Resumen: El presente ensayo: Educación y trabajo: ¡Un binomio que suscita ideas para ser libre y dignos de verdad, intenta hacer una valoración crítica de la importancia que tiene la educación y el trabajo como instrumentos válidos para la formación de productores de calidad y ciudadanos plenos para el ejercicio de la democracia de alta intensidad, en un escenario de crisis de la civilización occidental capitalista en su fase de globalización neoliberal, a la que no es ajena el Perú; y cómo en este contexto la educación peruana se encuentra sumida en una profunda crisis, y más aún, donde las élites dominantes a nivel nacional e internacional pretenden desconocer la importancia que tiene el binomio y trabajo, para suscitar ideas para la formación de seres libres, autónomos, responsables y dignos de verdad. 
Intenta dar algunas coordenadas para transitar por nuevos caminos para tejer futuros de liberación para corazonar el mundo.

Palabras-claves: Binomio educación y trabajo. Seres libres, autónomos, responsables y democráticos. Democracia de alta intensidad. Globalización neoliberal. Sujetos erguidos y desafiantes. Escuela para el trabajo digno libre y liberador. Crisis de la educación y sociedad peruana.

Abstract: The present essay: Education and Work: A combination that raises ideas to be free and really worthy, try to make a critical assessment of the importance of the education and the work as valid way for the formation of quality producers and full citizens for the exercise of high intensity democracy in a scenario of crisis of the capitalist Western civilization in its neoliberal phase of globalization, which it is no stranger to Peru; and like in this context Peruvian education is mired in a deep crises, and moreover, where the ruling elites nationally and internationally ignore the importance of the binomial and work, to make ideas for the formation of free, autonomous, responsible and worthy human beings of truth. Try to give some coordinates to move in new ways to weave future release for corazonar the world.

Keywords: Work. Education. Citizenship. Globalization. Neoliberalism. Democracy. 


\section{Introduccion}

El presente y el futuro del desarrollo humano y la democracia se encuentran íntimamente ligados al binomio educación y trabajo como herramientas alternativas para formar al nuevo hombre del siglo XXI. Es decir, a un nuevo sujeto erguido y desafiante a las decisiones políticas de quienes ejercen el poder del Estado en un contexto marcado por la crisis de la civilización occidental capitalista en su fase de globalización neoliberal, que está destruyendo no solo el planeta, sino también a los seres humanos, y cuyos efectos negativos lo sentimos millones de personas desempleadas, familias sin hogar, hambrunas, epidemias masivas y violencias múltiples (LAO-MONTES, 2012).

Educación y trabajo: ¡Un binomio que suscita ideas para ser libres y dignos de verdad!, es un tema necesario e indispensable para la reflexión y la comprensión de este proceso de globalización neoliberal, "revolución" que avanza desigualmente en diferentes regiones y culturas como un torbellino de cambios que llega hasta el corazón mismo de nuestras vidas emocionales ${ }^{1}$. A trece años del siglo XXI y a casi veinticuatro años de vigencia de la Convención sobre los Derechos del Niño, la educación peruana hoy en día, está sumida en una profunda crisis y desligada del trabajo como una actividad que nos enseña a crecer en dignidad y humanidad, que nos ayude a reconocernos como sujetos erguidos y desafiantes a esta sociedad injusta (ZEMELMAN, 2010). Sin embargo, no todos somos conscientes de ello, especialmente la clase política, ignora que estamos ante una crisis sistémica y profunda del capitalismo global, cuyas raíces se hunden en la misma organización de la sociedad. 
El presente ensayo, además de contribuir a tomar conciencia sobre los problemas más relevantes del mundo contemporáneo, procura incentivar la reflexión y el debate respecto al rol transformador de la realidad que cumple el binomio educación y trabajo, como instrumentos para el desarrollo social y económico que el sistema actual imposibilita. Como educadores y/o trabajadores sociales tenemos la obligación de desmentir a los defensores del pensamiento hegemónico neoliberal, que pretende desligar la educación del trabajo, para mantener la dictadura del gran capital. Entonces, el primer paso para una acción responsable y efectiva, es la reflexión y el debate crítico y propositivo.

Sin duda alguna, el binomio educación y trabajo, constituyen una nueva alternativa para la formación de conciencias transformadoras, liberadoras, emancipatorias capaces de ejercer sustantivamente la democracia y los derechos humanos, dos de las más grandes conquistas políticas del siglo XX. La educación y el trabajo, hermanos siameses en este concierto de nuevo liberalismo económico que propone la universalización de las leyes económicas y la exigencia de la transnacionalización de las economías para la modernización de las sociedades (UGARTECHE, 1997), han sido condenados a vivir de espaldas. Es por ello, tienen que juntarse como un solo ser, para contribuir al proceso de emancipación del país, y de este modo lograr que los sujetos y los pueblos dejen de ser meros individuos, y convertirse en agentes de su propio desarrollo, gracias a su capacidad transformadora ${ }^{2}$. El binomio educación y trabajo, no deberían ser solo el privilegio de pequeñas élites, sino derechos humanos que garanticen la dignidad y la libertad del hombre, lo que constituye "la clave esencial de la 'cuestión social"', además promueven la dignidad del ser humano y, el justo 
reconocimiento de sus derechos y deberes y, lo más trascendente, desarrollan la cultura del trabajo y denuncian toda injusticia ${ }^{3}$.

Ahora más que nunca, el binomio educación y trabajo, tienen que darse la mano en la escuela como espacio social, para así contribuir al desarrollo de las capacidades y habilidades del ser humano. Por tanto, la educación y el trabajo digno, libre y liberador como actividad que suscita ideas, tiene que educar a los niños, niñas y adolescentes para la comprensión de los procesos económicos, sociales, políticos y culturales, a fin de aguzar su capacidad rebelde, emancipadora y liberadora que los lleve a rechazar la lógica del mercado que está destruyendo al ser humano y la Madre Tierra, y cuyas consecuencias nefastas son la mercantilización de la humanidad que nos impide el Buen Vivir ${ }^{4}$. Hoy en día, la educación y el trabajo, junto con la economía de la felicidad, deberían comenzar por ser las ciencias, que estudien la conservación del hombre y la naturaleza, promoviendo el trabajo digno, libre y liberador, como oposición al trabajo explotado, alienado, mercantilizado e instrumento de subordinación del ser humano.

Lima, mayo de 2013.

\section{Perú: país diverso y tierra y generosa que nos acoge e inspira esperanza}

El Perú, es un país de grandes contrastes, contradicciones, encuentros y desencuentros históricos, ilusiones y frustraciones insólitas. Es una tierra diversa y generosa que nos acoge e inspira a seguir nadando contra la corriente, pero con alegría, optimismo 
y esperanza para hacer del binomio educación y trabajo instrumentos de dignificación del ser humano, y así enfrentar con éxito la crisis del capitalismo, y por ende del sistema educativo y de la misma sociedad. Estamos obligados a defender nuestros mitos y utopías, a pesar de los tiempos de incertidumbre, desesperanza y ambivalencia, en el contexto de globalización ${ }^{6}$ que nos impone una organización educativa que tiende a mantener las diferencias sociales preexistentes desde la época colonial.

Desde aquellos tiempos históricos, las élites políticas gobernantes de nuestro país, adrede han menospreciado la importancia que tiene el binomio educación y trabajo como medios facilitadores para contribuir al desarrollo humano y la construcción de una democracia de alta intensida ${ }^{7}$, y más aún, donde la escuela, desligada del trabajo, histórica y sistemáticamente ha reproducido, $\mathrm{y}$ sigue reproduciendo la desigualdad, la pobreza y exclusión desdeñando de esta manera el rico capital cultural que tiene nuestro país. El sistema escolar peruano siempre ha estado divorciado del trabajo como actividad que forma a individuos libres, autónomos y democráticos ${ }^{8}$.

El Perú es un espacio social y geográfico en cuyo territorio coexisten diversidad de culturas: en la Costa, el Ande y la Amazonía. Así, podemos encontrar una rica y envidiable trama de diversidad cultural. Asimismo, en sus exuberantes y ubérrimos valles costeños, andinos y amazónicos florecen variedad de zonas de vida que existen en el mundo, tipos de clima, especies de aves, especies de mamíferos, de plantas nativas, medicinales, de uso alimentario, ornamental y forestal. En el océano abunda una rica diversidad ictiológica y reservas petrolíferas. Las entrañas de los Andes contienen ingentes reservas minerales; y en la enigmática región amazó- 
nica se hallan envidiables recursos petroleros, gasíferos, forestales y ricas fuentes de agua dulce. Esta inmensa despensa natural que es el Perú, cualquier país del mundo apetecería tenerla9.

Estas naturales ventajas, lamentablemente nunca fueron aprovechadas debidamente. La educación en nuestro país jamás se ocupó de enseñar a comprender y revalorar la cultura del trabajo, que es nuestra génesis y matriz histórica. La educación desligada del trabajo, en ese espacio social que es la escuela, nos deformó y nos "enseñó" sólo a transformar la naturaleza, desde una lógica depredadora y la razón instrumental occidental. Nunca nos educó para valorar el trabajo como la actividad organizadora de nuestras vidas, ni mucho menos, para establecer una relación amorosa y respetuosa del hombre con la naturaleza. En suma, la educación y la escuela en el Perú, correspondieron siempre a la razón que privilegia la riqueza y la casta ${ }^{10}$.

Coincidimos plenamente con José Carlos Mariátegui, cuando afirmaba que la educación nacional, y por ende la escuela pública, frecuentemente carecieron de un espíritu nacional. Impregnadas de un espíritu colonial y colonizador; jamás se preocuparon en formar productores y ciudadanos respetuosos del ser humano y la naturaleza ${ }^{11}$. La educación y la escuela pública mantienen todavía un espíritu colonial y colonizador: siempre preocupado en transformar la naturaleza para la extracción y exportación de materias primas a los países metropolitanos. El mismo espíritu se manifiesta en la educación pública cuando no trata a los pobres como peruanos iguales a todos los demás, sino como máquinas de producir riqueza mediante la mercantilización de su fuerza de trabajo. Entonces, la República no se diferencia de ese terreno virreinal y colonizador ${ }^{12}$. 
Heredamos de la colonia y la república oligárquica una educación con un concepto eclesiástico y literario de la enseñanza para las castas ilustradas; y de subordinación y sumisión para los indígenas y afroperuanos. Con este concepto la escuela se abría, como espacio social, sólo para los criollos y mestizos, y se cerraba para los indígenas y los afrosperuanos. La educación era y sigue siendo privilegio de castas, élites y de quienes pueden pagarla. El pueblo no tiene el derecho a una educación y escuela que forme a los niños, niñas y adolescentes en el trabajo, por el trabajo y para el trabajo. Después de más de cinco centurias de dominación, la educación y la enseñanza sólo se dedican a formar clérigos, doctores, tecnócratas y militares de la élite insensibles e indolentes; y en el seno del pueblo a formar súbitos o siervos, menos a productores y ciudadanos ${ }^{13}$.

Nuestra constatación es que la educación y la escuela en el Perú, jamás tuvieron una política educacional que coadyuve al desarrollo humano de los sectores más desposeídos de la sociedad. Así, nacía La República en la miseria por obra y gracia de las castas oligárquicas. Después de transcurrido el siglo XX y a trece años del siglo XXI, aún no tenemos un Proyecto Educativo Nacional que nos ayude a salir de la mediocridad. ${ }^{14}$ Nuestro gran reto es construir un nuevo pacto social dándole contenido concreto y positivo al buen gobierno y buen vivir desde nuestras múltiples trincheras de lucha y dimensiones de vida. En este sentido, un modo de recrear el quehacer crítico desde la educación y el trabajo como un proyecto de descolonialidad del poder, desde cada sujeto, desde cada lugar, para tejer futuros de liberación para corazonar el mundo (LAO-MONTES, 2012). 


\section{Imaginarios, saberes y lenguajes en disputa: reflexiones sobre la importancia de la educación y el trabajo, para formar productores y ciudadanos}

Como bien afirma Lao-Montes (2012), no podemos negar que hoy en día vivimos una situación de caos estructural en el sistema-mundo moderno/colonial capitalista que nos afecta seriamente a todos y todas. Sin embargo, desde organismos internacionales imponen a los gobiernos de América Latina y los mal llamados países en vías de desarrollo de África y Asia, el lenguaje simplista y engañoso de la erradicación y abolición del trabajo infantil, olvidando que en nuestros imaginarios, saberes y lenguajes el trabajo digno, libre y liberador es una actividad festiva, ritual en nuestras culturas y pueblos. Ante este intento de imponernos una matriz cultural occidental, y ante una ofensiva feroz de promover "acumulación por desposesión" de tierras y recursos naturales que explican las ofensivas de recolonización del nuevo capitalismo extractivista $^{15}$, los peruanos estamos obligados a reflexionar e inspirarnos a recuperar el amor por la naturaleza, por nuestra cultura ancestral donde el trabajo era y sigue siendo una actividad donde se practica la solidaridad y reciprocidad como modos de vida para el buen vivir. Hoy más que nunca, se impone la necesidad de reivindicar la importancia del binomio educación y trabajo para formar productores y ciudadanos. Son los temas centrales de la problemática educativa actual. La base de esta relación está en la educación y el trabajo, ya que este tipo de educación aprovecha la riqueza de los recursos naturales y la experiencia del trabajo como un medio educativo, que permite eliminar la separación existente entre el trabajo intelectual y el trabajo manual y, facilita la igualdad 
de oportunidades para el desarrollo de las capacidades y habilidades como medios de promoción social y ocupacional para vivir con dignidad ${ }^{16}$.

Ninguna educación alcanzará su finalidad más profunda, si no capacita a los educandos para el trabajo, si no permite y promueve la habilitación de los niños, niñas y adolescentes para la actividad creadora y recreadora en el mundo. Educar para el trabajo es condición esencial para la realización del hombre en todas sus dimensiones. (SALAZAR BONDY, 1996) ${ }^{17}$. Ante la deshumanización del mundo y de cada uno de nosotros, estamos llamados y obligados a rescatar la importancia de la educación y el trabajo que nos humanice y ayude a iluminar el camino para la defensa de la vida, del medio ambiente y la justicia social, que son dimensiones éticas fundamentales de la educación.

Si de verdad creemos en "otro Perú y otro mundo posible", parafraseando a Gabriel García Márquez, diremos que no sólo hay que poner "el país al alcance de los niños", hay que poner el mundo al alcance de las personas, de los pueblos, los maestros y las maestras, los trabajadores sociales, los niños, niñas y adolescentes. Esto significa disputar los imaginarios, saberes y lenguajes a los defensores del pensamiento único neoliberal; y grabar en nuestras mentes y corazones la importancia que cobra la educación y el trabajo. Solo así, estaremos en la capacidad de recuperar las luchas, los sueños, las esperanzas de todos los demás pueblos de la Tierra, interesarnos por sus culturas y junto con ellos combatir lúcida y eficazmente aquello que nos desconcierta debido a la imposición de los intereses del libre mercado ${ }^{18}$. El Perú nos inspira esperanza para revalorar nuestra rica diversidad cultural basada en el trabajo, y nos llena de fuerzas para hacer frente a aquellos que pretenden gobernarnos en una "democracia" que, cada vez 
más, se convierte en el simple revestimiento de la sacrosanta ley de libre mercado, acción apoyada por la educación occidentalizada y los medios de comunicación dominantes.

\section{La crisis silenciosa de la educación en un contexto de neoliberalismo inculto, dogmático y fuera de contexto}

La educación y el trabajo constituyen el factor clave para el desarrollo humano; incluso hay quienes le otorgan el rango de factor esencial e indispensable de dicho desarrollo. Mediante la educación y el trabajo el niño, el hombre y la mujer tienen la posibilidad de poseer y disfrutar una vida más plena, más digna, más libre y autónoma para alcanzar mejores alternativas ocupacionales acordes con la condición humana. Alternativas de información, de recreo, de goce pleno de derechos, y por ende, más oportunidades de crecimiento de sus capacidades y habilidades para gozar de una mejor calidad de vida. Un intelectual de la talla de Fernando Savater afirma, con razón, que "la educación es sin duda el más humano y humanizador de todos los empeños", y que "nacemos humanos pero eso no basta: tenemos que llegar a serlo". La educación ${ }^{19}$ y el trabajo serán vehículos fundamentales para posibilitar que los demás contagien su humanidad ${ }^{20}$. No obstante ello, actualmente la educación peruana vive una crisis silenciosa en un contexto de neoliberalismo económico y autoritarismo político pretende convertir a las presentes y futuras generaciones de los sectores populares en seres insignificantes y buenos subalternos.

No debemos perder de vista que la educación y el trabajo demanda investigación y comprensión de los hechos sociales, económicos, políticos y culturales. No hay educación sin trabajo, ni 
trabajo sin educación. Estas actividades se encuentran cada uno en el cuerpo del otro. Mientras se enseña en el trabajo, se continúa buscando, indagando para la comprensión de la realidad. Asimismo, se investiga para comprobar y conocer aún lo que no se conoce y así comunicar o anunciar la novedad de un mundo nuevo que ofrezca una felicidad plena a los seres humanos ${ }^{21}$.

\section{¿Por qué la educación peruana está en crisis y en una inmensa sala de cuidados intensivos?}

En el actual momento histórico, estamos viviendo en medio de una crisis de proporciones gigantescas y de enorme gravedad a nivel nacional y global. No sólo hay crisis económica, también existe la silenciosa crisis que actualmente atraviesa la educación peruana. Crisis corrosiva que, de no ser tratada radicalmente con una verdadera revolución educativa que revalore el binomio educación y trabajo, puede llegar a ser mucho más perjudicial para el presente y el futuro desarrollo humano y la democracia en el Perú. Este es el gran peligro al que nos ha conducido la modernización neoliberal de gobiernos indolentes ganados por la agresividad, soberbia y demagogia.

El problema fundamental de la crisis de la educación peruana no es pedagógico, ni mucho menos económico, sino político ${ }^{22}$. Esta priorización no significa dejar de lado los problemas económicos y/o propiamente educativos, sino precisar la naturaleza del problema que impide la comprensión de los hechos sociales, económicos, políticos y culturales. Como problema político, nos referimos a la falta de voluntad política de los sectores sociales invo- 
lucrados -especialmente de los diversos gobiernos de turno-, para reformar la educación peruana, así como a la falta de conciencia de políticos y especialistas en el tema, sobre la necesidad específica de construir consensos para superar audaz y creativamente la crisis de la educación ${ }^{23}$.

No pretendemos decir que a la clase política no les interese o importe la educación, simplemente queremos señalar que les interesa más como fuente de recursos para nutrir a sus clientelas, antes que como sector fundamental a transformar para que la formación de nuestros niños, niñas, adolescentes y jóvenes contribuya al desarrollo nacional y democrático del país. La clase política trata la educación sólo como un tema más de su gobernabilidad tradicional y práctica autoritaria y antidemocrática. Es decir, como una moneda de cambio que ponen en acción cuando pueden obtener alguna ventaja. Esta es una dinámica y práctica "normal" en la política peruana que ha ahondado la crisis de la educación en estos últimos veintitrés años de neoliberalismo inculto, dogmático y fuera de contexto ${ }^{24}$.

Ahora bien, a manera de ejemplo de la falta de decisión política para remediar la crisis de la educación, podemos señalar que entre los años 2000 y 2004 el gasto público en educación básica tuvo un incremento del 27\%; el mismo que se gastó en aumento de remuneraciones, que crecieron como porcentaje del gasto en el mismo nivel educativo del 87 al 94\%, no dejando casi nada para la inversión. Esta tendencia no es gratuita, responde a criterios monetaristas primitivos de reducir la inversión pública como una manera de controlar la inflación, sin importar que esta reducción afecte gravemente la calidad de vida de la población (MEF 2005). Esta tendencia se llevó al extremo en los últimos años reduciendo 
la inversión pública como porcentaje del PBI de 4,7\% en 1994 a 2,8\% en el 2004 (página web del banco Central de Reserva del Perú, 2005). Por lo tanto, la bancarrota de la educación en el Perú no se supera con esfuerzos parciales, sino con una verdadera y radical revolución educativa que incluya una visión y un programa de conjunto ${ }^{25}$.

\section{¿Cómo salir del laberinto para superar la crisis de la educación?}

“¡Y no hay remedio!” Así exclamaba, hace más cuatrocientos años, el cronista indígena Guamán Poma de Ayala frente a los abusos y horrores de genocidio y etnocidio del 'orden colonial'. Esta frase bien podría servir para expresar el sentimiento que nos produce el examen de nuestros males contemporáneos, particularmente cuando se trata de la crisis de la educación ${ }^{26}$. Ante la crisis de la educación peruana ${ }^{27}$, parafraseando a Augusto Salazar Bondy, necesitamos una educación de la crisis y para la crisis; y esa es una educación para el trabajo, en el trabajo y por el trabajo. Lo cual significa hacer de la educación y del trabajo un esfuerzo dirigido a levantar el nivel educativo y la calidad de vida de los peruanos para contribuir al desarrollo del país. Entonces, cada niño, niña y adolescente que trabaja en el Perú, debería estar educándose de alguna manera, adiestrándose de alguna manera para la prosperidad, el progreso y el buen vivir. Cada hombre que se eduque, el niño, niña, el joven, el adulto, debe estar imbuidos de la alta misión patriótica que la colectividad se ha impuesto. $\mathrm{Y}$ a fin de lograrlo, nuestra escuela debe estar en todas partes y adoptar todas las formas de enseñanza en la clase, la calle, el taller, el campo, el cuartel, y operar desde todos los rincones del país promoviendo 
la comprensión de los procesos económicos, sociales, políticos y la importancia que cumple el trabajo en este proceso $^{28}$.

La educación y el trabajo son derechos humanos, universales, integrales, indivisibles, inalienables e irrenunciables. Los niños, niñas y adolescentes tienen el derecho de disfrutar de una educación basada en el trabajo que les ayude a ampliar su horizonte de sentido y que los prepare mejor para elegir su destino. Y no simplemente para seguir los dictados de los defensores del discurso hegemónico abolicionista del trabajo, propuesto por la OIT. Organismo desesperado en busca de feligreses para conseguir el éxito que aún no ha logrado, luego de décadas de predicar que el trabajo impide a los niños, niñas y adolescentes el desarrollo de sus capacidades, el pensamiento crítico, el análisis lógico y la imaginación. La falsa noción de que el trabajo es negativo, es un mensaje que pretende que ignoremos que actualmente vivimos un proceso de globalización que significa también, en muchos aspectos, globo-colonización ${ }^{29}$, fenómeno que ahonda las diferencias y amenaza las singularidades culturales ${ }^{31}$.

Ante este panorama cargado de negros nubarrones, nuestra misión es seguir luchando por el cambio y la transformación de la educación y la escuela. Cambio que debe tener como sustento pedagógico el trabajo y que prepare a los niños, niñas y adolescentes, no sólo para el ejercicio de la ciudadanía, sino también para la comprensión de la vida social, y para que sean excelentes productores y, sobre todo, para darle un sentido más humano a nuestras vidas $^{32}$. Desde las mismas entrañas de nuestro pueblo, tanto desde el pensamiento filosófico, teológico, ético, político, así como religioso, que piensa en el Dios de la Vida ${ }^{33}$, existen experiencias educativas innovadoras desde la niñez trabajadora ${ }^{34}$, y así contribuir a 
superar la crisis de la educación. El "poder” hegemónico en lugar de avasallarnos, nos abre paso a una lógica distinta, no de producción irracional de bienes materiales que agota a la Madre Tierra, sino de generación de valores: trabajo digno, humanidad, solidaridad y reciprocidad para recuperar la gratuidad del amor y respeto a toda forma de vida. Así como se globalizan la explotación, el terror, la violencia, la indolencia y las diversas formas de matar, se globalizan también la lucha por la justicia social, la paz, la defensa de los derechos humanos, la diversidad cultural $^{34}$, y el derecho a una educación que se sustenta en el trabajo como actividad que suscita ideas para el rescate de la condición humana. El trabajo, en condiciones dignas, no perdamos de vista, es el gran organizador de la vida de los niños, niñas y adolescentes en el país ${ }^{35}$.

\section{Perú, país de contradicciones y demagogia: “¿revolución silenciosa en educación?”}

NOS DICE EL HISTORIADOR CARLOS CONTRERAS que "el siglo veinte peruano ha sido el siglo de la educación en el Perú. Nunca antes se puso un empeño tan vasto en abrir escuelas, colegios y universidades en las diversas regiones del territorio nacional. Iniciativas que corrió más de lado del Estado, que de los sectores privados o la sociedad civil"36.

Y tiene razón: el acceso a la educación creció en el Perú desde inicios del siglo XX, pero se aceleró explosivamente desde 1950. Primero, se masificó el acceso a la educación primaria, lo que dio lugar a la reducción del analfabetismo y la generación de nuevas expectativas en zonas rurales: con la expansión de la cobertura 
educativa, parecía hacerse realidad un camino para el progreso de amplios sectores. A partir de las décadas de 1950 y 1970 se produjo el auge escolar de la educación secundaria. Los peruanos en general, y en especial los sectores pobres y rurales, depositaron sus esperanzas y dedicaron esfuerzos en hacer realidad el denominado "mito de la escuela". Es decir, lograr movilidad social - lo que en el lenguaje cotidiano significa "superación"- a través de la educación (WILSON, 2001). La fuerza de ese mito llevó en las décadas siguientes a una masiva presión para ampliar la educación en todos sus niveles ${ }^{37}$.

La educación peruana históricamente ha mantenido un tipo de escuela que nunca preparó a los niños, niñas y adolescentes para la vida y el trabajo digno. Como tampoco los ayudó a enfrentar el porvenir, y ni siquiera a lidiar con el presente. Este anticuado modelo de escuela se aferra a un pasado ya finiquitado, como esas mujeres envejecidas que tuvieron un merecido éxito en su juventud, y ahora no quieren cambiar nada de su género ni de la moda a la que debieron el éxito, y condenan la evolución y los cambios que no son de su mundo ${ }^{38}$.

Así, en un contexto de abandono estatal de la inversión en la educación pública, cuestión que demostraré más adelante, dicha institución se transforma en un campo de disputas políticas. De este modo, la educación pública ha perdido su función social sin hacer un esfuerzo por formar trabajadores, productores y ciudadanos para atender los problemas sociales del país. Si bien la educación de alguna manera es el medio para remediar los problemas sociales, las soluciones deberían ser dadas a partir de una transformación de la colectividad. En medio de esta crisis educativa, la sociedad debería tener la capacidad de recusar la modernización 
neoliberal que nos impide salir de la pobreza y desigualdad. La escuela representa sólo una parte de esa inmensa colectividad.

Por más planes y propósitos que tenga la acción educativa, estos caerán en el vacío si no se educa para el trabajo, en el trabajo y por el trabajo. La escuela tiene una función importante en el quehacer social, y debería ayudar al país en su movimiento transformador. Por lo tanto, la escuela tiene que ser un espacio social que forme a los niños, niñas y adolescentes en la valoración crítica del trabajo ${ }^{39}$, y para el ejercicio pleno y sustantivo de la democracia de alta intensidad.

\section{la soledad de la educación y la escuela pública una paradoja}

En la última década del siglo XX, a nivel mundial se produjo un cambio de época y bifurcación histórica con la caída del Muro de Berlín y el derrumbe de la Unión Soviética, con el aparente triunfo del neoliberalismo y el "fin de la historia" ${ }^{40}$. Pero por otra parte, paradójicamente los Estados del mundo aprueban la Convención sobre los Derechos del $\mathrm{Niño}^{41}$, -que en sus artículos 28 y 29 reconoce el derecho a la educación- y se convierte en el instrumento jurídico más importante de los derechos de los niños urbi et orbi, ratificado en un tiempo récord por más de 176 Estados, entre los que se encuentra el Estado peruano, a excepción de EE.UU. y Somalia.

A inicios de los años 90 el Perú, a pesar de la vigencia de la Convención sobre los Derechos del Niño, padecía, desde la guerra con Chile, una de sus más desastrosas crisis: económica, política, social y moral. Recesión e hiperinflación escalando a cifras nunca 
antes vistas, del rango del 3000\%, subversión, narcotráfico, guerra sucia, corrupción y anomia social. En el mes de julio, tras una reñida campaña electoral, se instauró un nuevo gobierno. Este nuevo régimen que prometió el respeto a los derechos humanos, no dudó un instante en decretar duras medidas económicas neoliberales para controlar la hiperinflación. Estas medidas incrementaron de un día para otro la pobreza y acentuaron con mayor fuerza las desigualdades, convirtiendo al Perú como por arte de magia en una sociedad estratificada ${ }^{42}$. El 5 de abril de 1992 se instaura un régimen autoritario y corrupto que impuso una nueva Constitución el año 1993 y creó un Congreso a su medida. El neoliberalismo aplicado "a la peruana" lo que en realidad logró fue potenciar (y en cierta manera institucionalizar) un sistema de dominación, desigualdad y pobreza educativa que ya existía. Sistema según el cual, quienes tienen más recursos económicos reciben una mejor preparación escolar, claro está, en el circuito de instituciones educativas privadas. De esta manera, un derecho humano como la educación, pasó a convertirse en burda mercancía que permite acumular riqueza a pequeñas élites financieras y políticas.

En la segunda mitad de la década de los $90^{43}$, cuando la violencia política había sido relativamente superada, con el régimen fujimorista se incrementaron la corrupción y la violación de los derechos humanos. Así, se profundizó la desconfianza en la justicia y se produjo la fractura del tejido social de la nación. La educación en el Perú ${ }^{44}$ no era ajena a este contexto tan perverso; y la crisis que sufría el país se agravó; crisis que venía de muchos años atrás. Durante los años 2006-2011, pese a los discursos grandilocuentes de "El Perú avanza" y a la expresión que vivimos una "revolución silenciosa" de la educación; y actualmente ante la demagógica 
propuesta de 'revolución educativa' e 'inclusión social', ésta sigue postrada en el sótano ${ }^{45}$ y sometida a respiración artificial, en una sociedad atravesada por la violencia indirecta o estructural, y la violencia simbólica hecha una forma de habitus, como no enseñaba Bourdieu. Somos casi los últimos en el mundo en comprensión lectora y entendimiento de las matemáticas.

Para una cabal comprensión de la soledad de la educación y la escuela, es necesario remontarnos a la Reforma Educativa de los años 70, considerada en su tiempo una de las mejores del mundo por su consistencia programática, que lamentablemente empezó a ser desmantelada durante la segunda fase del gobierno militar de Francisco Morales Bermúdez en 1976. Posteriormente, siguió también durante los años 80 con la vuelta de la 'democracia', y es en el segundo gobierno de Fernando Belaunde Terry cuando se le extiende la partida de defunción. Todos los avances logrados desembocaron en el modelo del sistema educativo antiguo de educación inicial, primaria y secundaria ${ }^{46}$. Desde aquella época este modelo educativo sigue vigente ${ }^{47}$.

Durante el primer gobierno de Alan García Pérez (1985-1990) la crisis de la educación se agrava y toca fondo, debido a la escasa profesionalización del magisterio nacional por el ingreso de personal sin formación pedagógica ${ }^{48}$, y a que muchos maestros deben dedicarse a otras ocupaciones empujados por la crisis económica generada por la hiperinflación desbocada. En el diagnóstico realizado el año 1993 por el Ministerio de Educación en cooperación con la UNESCO, el Banco Mundial, GTZ y el PNUD, se señalaba que los rasgos más saltantes de esta crisis eran:

- Administración y gestión del sector inadecuada e incompetente. 
- Primacía de criterios políticos y burocráticos sobre el técnico-pedagógico.

- Sistema de regulaciones que no fomenta la iniciativa, no evalúa a los funcionarios y no tiene mecanismos para exigir la rendición de cuentas.

- Ineficiente ejecución debido a:

- Falta de textos y materiales educativos en el aula.

- Uso de metodologías inadecuadas.

- Inadecuada preparación de los docentes que usan metodologías obsoletas.

- Malas condiciones de trabajo de las escuela.

- Debilidad institucional de las escuelas ${ }^{49}$.

El sistema se encontraba altamente burocratizado, clienteizado y centralizado y en el cual dominaban las relaciones de orden tutelar verticales y autoritarias: el rol de los directores de los centros educativos se encontraba restringido a los órganos intermedios (USE / Zonas de Educación), que no eran capaces de desempeñar el rol de asesoría y supervisión para los que fueron creados. Trece años después del siglo XXI estos problemas aún no han sido superados.

En esta era de la soledad, la incertidumbre, la "revolución silenciosa de la educación", la "revolución educativa e inclusión social", en el marco de un inusitado crecimiento económico, atravesado por la violencia social ${ }^{50}$, la educación y la escuela viven una triste paradoja. De ella no podemos esperar nada y de ella esperamos todo. La educación y la escuela, dicen los exegetas de la desolación, atraviesan una crisis sin precedentes, y son incapaces de responder a los desafíos que los nuevos tiempos imponen y exigen. En una sociedad "del conocimiento y de las comunicaciones" -dicen- la 
educación y la escuela pierden su calidad, dinamismo, flexibilidad, dejando la formación de las presentes y nuevas generaciones en manos de los medios de comunicación, de las redes virtuales y de toda una parafernalia tecnológica que, en apariencia, regula la vida de los individuos en el presente y la regulará aún más en el futuro ${ }^{51}$.

Ahora bien, a la educación y escuela se les atribuye buena parte de las penurias que viven hoy los ricos y pobres, incluidos $y$ excluidos, integrados y segregados. Si hay desempleo, es porque la educación y la escuela no forman personal adecuado a las demandas del mercado de trabajo (los ricos se perjudican porque no pueden "producir", los pobres porque limitan sus posibilidades de acceso a la riqueza acumulada). Si hay violencia es porque la educación y la escuela no transmiten valores de paz y de convivencia amorosa, respetuosa y equilibrada entre los seres humanos (los ricos se recluyen militarmente en ghettos de lujo, mientras los pobres están confinados y condenados a vivir en las grandes periferias urbanas, donde la miseria y la violencia cobran diariamente la vida de decenas de personas, gran parte de ellas jóvenes, adolescentes, niños y niñas). En este escenario, donde el tráfico de drogas, la corrupción ${ }^{52}$ e impunidad no se combaten radicalmente, la desnutrición familiar casi endémica se ahonda, donde el trabajo digno y la solidaridad no existen, se exacerba el individualismo y se pulverizan los vínculos sociales y afectivos, por consiguiente, la educación y la escuela fracasan en su función de educar para el desarrollo humano y la democracia ${ }^{53}$.

Muy a nuestro pesar, hoy en día, la escuela es tomada por importantes actores sociales de la comunidad educativa, solo como un centro productor de papeles y ya no, como debería ser, un centro productor de saberes y disputas de imaginarios y lenguajes. 
Esta distorsión tiene grandes efectos en la demanda por educación que se sigue centrando en fundar nuevas escuelas, construir más locales y, en menor medida, crear nuevas plazas docentes. Todo esto permite a los políticos y gobernantes hacer gala de su demagogia y a muchos estudiantes y padres de familia perder de vista la importancia de los conocimientos pertinentes para la vida en sociedad. Esta concepción de la escuela como productora de papeles, quizá sea la idea más importante que haya que dejar de lado para cambiar la educación en el Perú ${ }^{54}$.

\section{Crecimiento económico versus inversión en educación: ¿qué clase de educación y desarrollo queremos para el perú?}

Actualmente, no podemos negar que el Perú atraviesa por un inusitado crecimiento económico, pero también por una transición democrática fallida y una prosperidad falaz ${ }^{55}$, lo que nos lleva a preguntarnos: ¿Hacia dónde queremos ir como sociedad?, ¿qué tipo de educación y escuela queremos para nuestros niños, niñas y jóvenes en el siglo XXI?, ¿cuál es el objetivo último que tenemos en nuestras políticas públicas y en especial en la inversión en educación?, ¿por qué y para qué debemos formar a nuestros niños y niñas, tomando en cuenta el binomio educación y trabajo?, ¿será posible transitar nuevos caminos que nos permitan conquistar el desarrollo humano y una democracia de alta intensidad?

Nuestra respuesta es sencilla: uno de los objetivos de la educación y el trabajo es formar productores de calidad, competitivos; y ciudadanos críticos y protagonistas para contribuir al desarrollo del Perú, así como también mejorar la libertad y capacidades de 
las personas de manera sostenible. Un enfoque real del desarrollo humano pone énfasis en la inversión en salud y educación, y en promover la participación protagónica de la ciudadana en las decisiones colectivas. Necesitamos un desarrollo humano con justicia social, para evitar que las inequidades en el acceso a los recursos y la falta de oportunidades condenen a millones de niños y niñas a la insignificancia y pobreza. Queremos y necesitamos una educación basada en el trabajo digno que fomente la defensa de los derechos humanos - especialmente los derechos económicos, sociales, culturales y ambientales -, y que el Estado garantice efectivamente estos derechos. Queremos un tipo de educación y trabajo que forme a las personas en el derecho a decidir su propia opción de desarrollo. En suma, necesitamos y queremos una sociedad educadora que trabaje por el respeto a las diferencias y por el diálogo intercultural y coadyuve a la construcción de una cultura de paz y justicia social ${ }^{57}$.

Si hacemos una comparación entre el ritmo de crecimiento económico y la inversión en educación en estos últimos años, tendremos ingratas sorpresas que echan por tierra la versión de la realidad social y económica nacional que nos ofrece el discurso triunfalista del gobierno y la prensa hegemónica adicta y morbosa, que no informa de la magnitud de la precariedad de la educación y la conflictividad social en la que vive gran parte del país ${ }^{58}$. Las datas que presentamos a continuación, nos pueden ilustrar de la paradoja existente entre crecimiento económico e inversión en educación. Rara paradoja que, por un lado, anuncia la inviabilidad de la educación y la escuela, su impotencia y futilidad, y, por otro lado, atribuye a la escuela todos los males que la sociedad sufre, así como coloca en ella toda la responsabilidad para que remedie 
dichos males. Rara paradoja que nos instala ante una dramática evidencia; por acción u omisión, la educación y la escuela están lejos de ser lo que se espera de ellas. Rara paradoja que conduce, por dos vías, a un mismo destino. Un destino donde el desencanto y la desesperanza de la educación y la escuela funden y confunden sus fronteras ${ }^{58}$.

\section{PERU: CRECIMIENTO ECONOMICO*}

\begin{tabular}{|c|c|}
\hline AÑOS & PORCENTAJE (\%) \\
\hline 2003 & 4.0 \\
\hline 2004 & 5.1 \\
\hline 2005 & 6.7 \\
\hline 2006 & 7.6 \\
\hline 2007 & 8.9 \\
\hline 2008 & 9.8 \\
\hline 2009 & 3.0 \\
\hline 2010 & 5.5 \\
\hline
\end{tabular}

* Estimación, 2010 proyección. Fuente MEF. Elaboración: CIE-CCL.

El monto que dedica un país a la educación permite dimensionar la importancia que ésta tiene en las políticas públicas. El Perú destina a la educación menos del 3\% del PBI y cerca del 15\% del gasto total, mucho menos que países como Chile, Brasil y México, incluso menos que el promedio de la Organización para la Cooperación y el Desarrollo Económico-OCDE, y lejos de países como Finlandia y Suecia (Ver tabla 1$)^{59}$. Se incumple la Política de Estado del Acuerdo Nacional, documento donde se garantiza dotarla de los recursos necesarios para la reforma educativa, otorgando un incremento mínimo anual en el presupuesto del sector educación 
al $0.25 \%$ del PBI, hasta que éste alcance un monto global equivalente al 6\% del PBI que garantice el acceso universal a una educación pública gratuita y de calidad ${ }^{60}$.

Tabla $\mathrm{N}^{\circ}$ 1. Gasto en educación como porcentaje del PBI y del gasto total

\begin{tabular}{|c|c|c|c|}
\hline PAIS & AÑO & $\%$ del PBI & $\begin{array}{c}\text { Gasto público } \\
\text { educación/Gasto PT (\%) }\end{array}$ \\
\hline Argentina $^{*}$ & 2004 & 4,0 & 13,1 \\
\hline Brasil $^{\star}$ & 2005 & 4,4 & 14,5 \\
\hline Chile $^{*}$ & 2006 & 3,4 & 16,0 \\
\hline Colombia $^{*}$ & 2006 & 4,8 & 14,2 \\
\hline $\mathrm{CUBA}^{*}$ & 2006 & 8,2 & 14,2 \\
\hline México* & 2004 & 5,3 & 25,6 \\
\hline Paraguay ${ }^{\star}$ & 2004 & 3,9 & 10,0 \\
\hline Perú & $\begin{array}{l}2005 \\
2006 \\
2008\end{array}$ & $\begin{array}{l}2,8 \\
2,6 \\
2,8\end{array}$ & $\begin{array}{l}16,1 \\
15,4 \\
14,7\end{array}$ \\
\hline Venezuela $^{\star}$ & 2006 & 3,4 & $\mathrm{Nd}$ \\
\hline $\begin{array}{l}\text { Promedio } \\
\text { OCDE}^{\star}\end{array}$ & 2004 & 5,4 & $\mathrm{Nd}$ \\
\hline Finlandia ${ }^{* *}$ & 2004 & 6,4 & $\mathrm{Nd}$ \\
\hline España ${ }^{* *}$ & 2005 & 4,2 & $\mathrm{Nd}$ \\
\hline Suecia** & 2004 & 7,2 & $\mathrm{Nd}$ \\
\hline EE. UU. & 2005 & 5,3 & $\mathrm{Nd}$ \\
\hline
\end{tabular}

Nota: Perú: Ministerio de Educación (2008ª)

* Organización de Estados Iberoamericanos (2008)

** Cámara de Diputados-Centro de Finanzas Públicas, México (2009) 
Ahora bien, del gasto público que el Perú dedica a la educación, el mayor porcentaje está destinado al gasto corriente, principalmente al rubro de remuneraciones, y no así a gasto de capital, es decir, a inversiones que este sector tan importante necesita para superar su estado de postración (ver tabla 2$)^{61}$.

Tabla $\mathrm{N}^{\circ}$ 2. Gasto público en instituciones educativas por tipo de gasto (\% del total)

\begin{tabular}{|c|c|c|c|}
\hline AÑO & CAPITAL & REMUNERACIONES & $\begin{array}{c}\text { BIENES, } \\
\text { SERVICIOS Y } \\
\text { MANTENIMIENTO }\end{array}$ \\
\hline 2005 & 8.5 & 82,1 & 8,8 \\
\hline 2008 & 16,1 & 70,0 & 13,0 \\
\hline
\end{tabular}

Nota: Ministerio de Educación (2008a)

Las datas precedentes nos indican la ínfima inversión en educación que está copado por el gasto corriente. Nos demuestra que la clase política no está interesada en convertir la educación y el trabajo en instrumentos que ayuden a superar la pobreza y desigualdad. Ignoran que la educación y el trabajo son indispensables en un país con un Estado minúsculo y desregulador que deja todo a la ley de libre mercado ${ }^{62}$, lo que ha hecho del Perú un país apenas industrializado y que prioriza sólo la exportación de materias primas $^{63}$. En este sentido, coincidimos con Rodrigo Montoya cuando dice que la ceguera occidental conduce a confundir la educación y el desarrollo con un conjunto de cifras y a creer que la vida humana consiste sólo en satisfacer algunas necesidades básicas. El universo de los afectos, de la alegría, del canto, de la música, del baile, de los ceramios y del placer no cuenta. El mundo se divide 
ahora entre los países llamados "del norte", que son elefantes tecnológicos con sentimientos de hormigas, y miles de pueblos en el llamado "sur", que saben vivir con alegría, optimismo y esperanza a pesar de los enormes sufrimientos que producen el dominio de unos sobre otros y la escasez de recursos. La ausencia o vigencia del principio de reciprocidad, según sea el caso, está en el fondo de esa división ${ }^{64}$.

\section{Contradicciones y tensiones: ¿educación para el mercado y el crecimiento económico, o educación para el trabajo digno, libre, liberador y la democracia de alta intensidad?}

Actualmente, la educación y la escuela en el Perú, afrontan contradicciones y tensiones en un mundo donde la nueva revolución tecnológica (la informática y las comunicaciones) y la nueva revolución política (la megalópolis emergente sobre las ruinas del Estado nacional con una democracia autoritaria) producen una nueva "revolución" social. Esta "revolución" social no es más que un reacomodo, un reordenamiento de las fuerzas sociales, principalmente de la fuerza del trabajo. Esto significa que cada día más trabajadores son encauzados hacia las actividades necesarias para incrementar la productividad y beneficiar a pequeñas élites económicas y financieras. El sistema de globalización ${ }^{65}$ neoliberal hoy opera como un gran megapatrón, concibiendo al mercado nacional y mundial como una empresa unitaria, administrada con criterios "modernizadores". Pero esta “modernidad" parece más cercana al bestial nacimiento del capitalismo como sistema mundial, que a la "racionalidad" utópica. La "moderna” producción 
capitalista en el Perú sigue basándose en la explotación del trabajo de millones de niños, niñas, adolescentes ${ }^{66}$, jóvenes, mujeres y el saqueo de nuestros recursos naturales ${ }^{67}$.

En este contexto tóxico, perverso y letal se encuentran en tensión dos paradigmas respecto de la educación. La educación para el mercado, el crecimiento económico y la competitividad ${ }^{68}$; y la educación para el trabajo digno, libre y liberador, para el desarrollo humano y la democracia de alta intensidad. La educación para el mercado y crecimiento económico es promovida por los defensores del viejo modelo capitalista. Ellos argumentan que el crecimiento económico redundará por sí mismo en beneficios como la salud, la educación y la disminución de la desigualdad socioeconómica. Sin embargo, los resultados de este viejo modelo conducen de manera concreta a institucionalizar la desigualdad. Los avances en materia de salud y educación guardan escasa correlación con el crecimiento económico, como ya lo hemos demostrado anteriormente. El crecimiento económico por sí solo no produce, necesariamente, democracia, ni mucho menos genera una población sana, comprometida y formada que disponga de oportunidades para una buena calidad de vida y el buen vivir de todas las clases sociales ${ }^{69}$.

La educación para el mercado, el crecimiento económico y la competitividad requiere de aptitudes básicas, alfabetización y competencia matemática. Asimismo, necesita de personas que tengan conocimientos más avanzados de informática y tecnología. Sin embargo, la igualdad en el acceso a la educación no reviste importancia para este modelo. Un país -como es el caso del Perú-, puede crecer sin dificultades, aunque los sectores más pobres de la población urbana y rural sigan siendo analfabetos y carezcan de los mínimos recursos básicos e informáticos. El paradigma de la 
educación para el mercado y crecimiento económico basado en el PBI per cápita, deja de lado la distribución equitativa y puede llegar a calificar positivamente a las naciones o Estados donde se registran alarmantes desigualdades. La educación para el mercado y crecimiento económico puede aumentar su PBI sin preocuparse demasiado por la distribución en materia educativa, siempre y cuando generen una élite competente para la tecnología y los negocios, con tecnócratas indolentes aptos para la sumisión o el servilismo ante la autoridad y la confianza en un líder o caudillo ${ }^{70}$.

\section{En medio de la tormenta y la "irrupción del pobre"71 en la búsqueda del binomio educación y trabajo}

Desde la otra orilla, como bien señala Gustavo Gutiérrez, en medio de la situación de pobreza ${ }^{72}$ y desigualdad asistimos a la “irrupción del pobre”, que sigue su curso navegando por grandes meandros, luchando siempre por el derecho a una educación para un trabajo digno, el desarrollo humano y la democracia de alta intensidad como principal alternativa y paradigma. Según este paradigma, lo que más importa son las oportunidades o "capacidades" que posee cada persona en ciertas esferas centrales que abarcan desde la vida, la salud y la integridad física, hasta la libertad política, la participación política y la educación. Este modelo de educación para el trabajo digno, el desarrollo humano y la democracia de alta intensidad, reconoce que todas las personas gozan de una dignidad humana y que ésta debe ser respetada por las leyes y las instituciones. Todo país o nación mínimamente decente y democrática debería promover que sus ciudadanos tengan 
todos los derechos. Un ingrediente esencial de toda vida dotada de humanidad y dignidad es tener el derecho a trabajar, además de tener voz y voto en la elección de las políticas que gobernarán la propia vida ${ }^{73}$.

En sus manifestaciones cotidianas en el aula, en los patios, en la relación profesor-alumno y entre los alumnos, la educación y escuela que tenemos en el Perú es autoritaria y excluyente. Por eso, en medio de la tormenta y la "irrupción del pobre", se lucha y construye desde los de abajo una educación para el trabajo digno, una educación para la ciudadanía portadora de un proyecto democrático para el país. Una educación que rechaza la educación tradicional que alienta y forma hábitos de obediencia ciega y sumisa, de la autoridad que ordena y no dialoga, del ejercicio del poder sin compromisos ni rendición de cuentas. Educación a través de la cual se refuerzan los perniciosos hábitos de discriminación étnica y de género impregnados en la sociedad peruana. Es, finalmente, una práctica educativa que produce como experiencia temprana para los niños y niñas del país el esquema de división entre ciudadanos plenos y los que no lo son ${ }^{74}$.

Ante esta situación, debemos reconocer que una de las funciones más poderosas que cumple la educación es la construcción de oportunidades para el trabajo digno, el desarrollo humano y la democracia y, a formar ciudadanos conscientes de sus derechos y de los derechos ajenos, seres abiertos a la solidaridad, a la crítica y a la participación protagónica. Por todo lo expuesto, tenemos que rechazar radicalmente los modelos tradicionales de educación que conciben a los niños y niñas como recipientes pasivos en los que se tiene que depositar la sabiduría de tiempos inmemoriales. He aquí la importancia que cobra la educación para el trabajo digno, 
el desarrollo humano y la democracia, para que los niños y niñas desarrollen su pensamiento activo, crítico, mediante la manipulación de los objetos, la observación, investigación, y la práctica de la solidaridad y reciprocidad. Una educación destinada a transformar al niño, niña y adolescente, en un ser autónomo, capaz de formar sus propios criterios independientes y de resolver problemas prácticos por sus propios medios, sin necesidad de recurrir a la "autoridad". En suma, la educación para el trabajo digno, el desarrollo humano y la democracia, progresa mediante la pedagogía de la ternura y la pedagogía de la pregunta, -¿por qué, para qué y cómo?- y la permanente crítica y autocrítica ${ }^{75}$.

\section{Nuestro eje, nuestro centro y nuestro corazón: la educación y escuela para el trabajo digno, libre y liberador}

La relación y necesidad que existe entre educación y la escuela para el trabajo digno, es el centro y el corazón de nuestras culturas: Costeñas, Andinas y Amazónicas. Ninguna educación podrá alcanzar su finalidad más profunda si no capacita para el trabajo, si no permite y promueve la formación de los niños y niñas para la actividad creadora y recreadora en el mundo. Educar para el trabajo digno, libre y liberador es, pues, condición esencial para la realización del hombre en todas sus dimensiones (SALAZAR BONDY, 1976). El animador de la vida desde la más tierna edad, el mejor fermento de la satisfacción sana y dinámica en el cuadro normal de la familia y la comunidad, no es el juego, es el trabajo $\left(\right.$ FREINET, 1974) ${ }^{76}$.

El trabajo tiene un inmenso valor formativo; por tanto, una educación y escuela para el trabajo, en el trabajo y por el trabajo, 
contribuirán a la formación del ser humano para el desarrollo de nuestro país. Ninguna enseñanza como la del trabajo y del taller, dirigida pedagógicamente, pone en actividad los sentidos, impulsa la creatividad, la autoactividad, desarrolla los fundamentos para todas las profesiones sociales y políticas y sirve a la formación ética y moral. El trabajo manual es plenamente educador porque inculca una moral, hábitos de laboriosidad, de responsabilidad, de emprendimiento y formas de conducta para la vida de la familia. Es indispensable que los niños y niñas aprendan a no desperdiciar ningún tipo de trabajo manual, y que a la vez cultiven en ellos hábitos para una vida sana y libre de todos los males contemporáneos que la sociedad de consumo nos ofrece actualmente ${ }^{77}$. No podríamos concebir una sociedad más democrática, justa y humana, si no se realizan cambios profundos en sus estructuras económicas, sociales, políticas y culturales, sin una educación y escuela que prepare a los niños y niñas para el trabajo, que les permita vivir digna y gozosamente en la sociedad.

\section{La educación y la escuela para el trabajo permiten al niño tener cabezas bien estructuradas y manos expertas mejor que odres bien llenos ${ }^{78}$}

La educación y la escuela para el trabajo son semillas que germinan desde las experiencias de las Escuelas de NNATs (Niños, Niñas y Adolescentes Trabajadores), o desde el trabajo pedagógico con los niños en situación de calle. A pesar de sus limitaciones de infraestructura, de la escasez de materiales y de maestros franciscanamente remunerados, la escuela y el trabajo son concebidas como el centro cultural más importante de la comunidad. 
Las condiciones en que se encaran los cambios educativos en estas escuelas, con niños, y niñas pobres y desnutridos, con padres desocupados y/o subocupados, a veces violentos y con carencias afectivas básicas, y más aún, con los vínculos sociales y afectivos fracturados, la educación y la escuela para el trabajo permiten a los niños y niñas a ser más libres, autónomos y responsables. Estas escuelas del trabajo son espacios sociales, donde se les ofrece a los niños y niñas espacios de escucha, amor, afecto y ternuras para el aprendizaje, donde la pedagogía de la ternura se está posicionando como un modo de actuar, que se pone al servicio de la lucha contra las seis formas principales de poder "en sociedades capitalistas" contemporáneas: patriarcado, explotación, diferenciación desigual, fetichismo de las mercancías, la dominación y el intercambio global desigual (SANTOS, 2006, p. 50) ) $^{79}$.

Estas experiencias de Escuelas de NNATs (Niños, Niñas y Adolescentes Trabajadores), acompañadas por el IFEJANT, se encuentran ubicadas en la Costa, el Ande y la Amazonía. Me refiero a las Escuelas Alejandro Cussiánovich, en Jaén y Lima (San Juan de Lurigancho); Escuela Graciela Villarán, en Jaén (Fila Alta); Escuela NASSAE, en Lima (San Juan de Lurigancho); Escuela San José Obrero, en Lima (Villa María del Triunfo); Escuela Colibrí, en Juliaca-Puno; Escuela en la isla de los Uros-Puno, y las emblemáticas Escuelas del MANTHOC, en Lima (San Juan de Miraflores), y Cajamarca respectivamente, que son verdaderos gérmenes de las escuelas del mañana. Cabe hacer mención de una pequeña experiencia emblemática de educación y trabajo, con niños en situación de calle, en la Asociación Niños del Río, gracias a la educación y el trabajo, estos niños están recuperando su dignidad y humanidad perdidas a tan temprana edad. Sin em- 
bargo, cabe precisar que en estas escuelas de niños trabajadores y en situación de calle, no significa que se haya de utilizar el trabajo manual como ilustración del trabajo intelectual escolar, ni que se oriente a los niños y niñas hacia un trabajo productivo prematuro, o que el pre-aprendizaje deba reemplazar en la escuela el esfuerzo del trabajo intelectual y artístico. El trabajo es y será el gran principio, el motor y la filosofía de la pedagogía de la ternura, la actividad de donde se derivarán todas las adquisiciones para tener cabezas bien estructuradas y manos expertas que son mucho mejor que odres bien llenos. En la sociedad del trabajo, la escuela, así regenerada, quedará por este mismo hecho perfectamente integrada al proceso general de defensa de la vida y el medio ambiente; será una rueda del gran mecanismo de transformación alternativa al pensamiento único neoliberal ${ }^{80}$.

En concordancia con lo expuesto hasta aquí, el trabajo tiene que ser entendido como fuente de humanidad y de sociedad, debe constituir sustento explícito de todo principio educativo. Se educa y debe educarse a los NNA siempre en el trabajo, por el trabajo y para el trabajo. Pero se trata del trabajo libre y liberador; y no de un trabajo alienado, mercantilizado y en consecuencia instrumento de la sujeción del hombre. (SALAZAR BONDY, 1976) ${ }^{81}$. Educar socialmente a partir del trabajo es brindar a los NNA una formación basada en valores y criterios de iniciativa, de sentido y pensamiento crítico, de libertad auténtica y plena, de responsabilidad, de autonomía y autoestima, de participación y organización protagónica $^{82}$ y de solidaridad. Esto es formar para el desarrollo humano, para la democracia vívida, también en la realidad educativa. 


\section{El binomio educación y trabajo para el desarrollo humano, la organización y participación protagónica para la democracia de alta intensidad en siglo XXI}

En un mundo signado por la globalización de la edad de hierro, al decir de Leonardo Boff ${ }^{83}$, que atenta peligrosamente contra la naturaleza, que la trata como una mercancía, como un banco de negocios y que está llevando a nuestro planeta a la destrucción en nombre del desarrollo, el progreso y la modernidad, de la rentabilidad, del mercado, de la competencia y de la búsqueda desenfrenada de necesidades superfluas de una sociedad de consumo; la escuela del trabajo para el desarrollo humano, la organización y la participación protagónica para la democracia de alta intensidad ayudarán a formar al hombre nuevo del siglo XXI, para hacer frente a los que sueñan con la erradicación del trabajo de los NNA, particularmente de los NNA del mundo rural Andino y Amazónico, como lo plantean muchos organismos internacionales, lo que constituye un atentado contra nuestras culturas, formas y modos de vida.

Intentar abolir el trabajo de los niños y niñas significa la imposición de un patrón cultural occidental también en el campo educativo, y es como si quisieran arrancar el corazón mismo de nuestras culturas. En suma, es pretender borrar de nuestras mentes y corazones la relación sagrada y respetuosa que se tiene con la naturaleza, con la Pacha Mama; y es también no comprender que el trabajo es un valor, fuente de vida, dignidad y creador de riqueza. Pretender afirmar que en nuestro país los niños y niñas trabajan porque son pobres, es ignorar el rico capital cultural de nuestros pueblos ancestrales; los niños y niños trabajan ${ }^{84}$ porque 
son considerados personas, sujetos económicos y políticos, por lo tanto, si de derechos se trata, ellos -los NNA- tienen el derecho como cualquier miembro de la comunidad a trabajar, pero en condiciones dignas y de acuerdo a sus capacidades y habilidades.

¿Qué lecciones y enseñanzas podemos sacar de este análisis en la búsqueda de lo que puede hacer la escuela del trabajo para el desarrollo humano, la organización y participación protagónica, para la democracia de alta intensidad en el siglo XXI?

- La escuela del trabajo puede ayudar a desarrollar las capacidades y habilidades de los niños y niñas para mirar el mundo desde la perspectiva del otro, en especial de aquellas personas que la sociedad suele representar como "objetos de protección tutelar" o seres inferiores.

- La escuela del trabajo debe inculcar a desarrollar la personalidad protagónica, la responsabilidad, la actuación social, política y económica para ser constructores de una sociedad más democrática, justa y humana para el buen vivir, porque entendemos que: "Ser protagonista, desarrollar personalidad protagónica, devenir un actor social, es tener dignidad y estar en la capacidad de amar $y$ ser amado" $"$.

- La escuela del trabajo debe promover el emprendimiento para desarrollar actividades socialmente justas, económicamente rentables y solidarias, y ecológicamente equilibradas.

- La escuela del trabajo debe fomentar la relación amorosa y respetuosa que debería existir entre el hombre y la naturaleza para aprender a vivir juntos y con dignidad en un mundo multipolar.

- La escuela del trabajo debe ayudar a promover activamente el pensamiento crítico, así como la habilidad y el coraje de ser insumisos ante las prácticas sociales autoritarias, asistencialistas, fatalistas, corruptas y discriminadoras que niegan la sustantividad humana y se oponen radicalmente a la democracia. 
Indudablemente, se trata de un plan muy ambicioso, vaciado de mitos y utopías, que deberíamos poner en marcha con un gran conocimiento y comprensión de los problemas económicos, sociales, políticos y culturales; y los recursos de cada lugar: la Costa, el Ande y la Amazonía, sin perder de vista en ningún momento las circunstancias sociales, económicas, políticas y culturales en la que estamos viviendo. Por tanto, es necesario aplicarlo no sólo en los contenidos curriculares, sino también en los métodos pedagógicos, y principalmente en la práctica social cotidiana en la familia, la escuela y comunidad.

\section{Referências}

ACUERDO NACIONAL (2007). Políticas de Estado. Lima: Acuerdo Nacional.

APARECIDA (2007). Documento final V Conferencia General del Episcopado Latinoamericano y del Caribe. Lima: Paulinas.

BALBI SACARNEO, Carmen Rosa, y Carlos ARAMBULO QUIROZ (2009). La Recomposición de las clases medias y el voto en el Perú. En: Cambios Sociales en el Perú (1968-2008). Lima: CISEPA, Facultad de Ciencias Sociales de la Pontificia Universidad Católica del Perú.

BAUMAN, Zygmunt (2005). Trabajo, consumismo y nuevos pobres. España: Gedisa Editorial.

BOFF, Leonardo (2003). Fundamentalismo, La globalización y el futuro de la humanidad. España: Sal Terrae.

BOFF, Leonardo (2006). Virtudes para otro mundo posible. I Hospitalidad y deber de todos. España: Sal Terrae.

BOURDIEU, Pierre (2005). Capital Cultural, Escuela y Espacio Social. Argentina: Siglo XXI Editores.

CAPELLA RIERA, Jorge (2002). Política Educativa. Lima: Impresos y Diseños S.A.C. Editores. 
CAPELLA RIERA, Jorge (2008). Teoría de la Educación. Facultad de Educación, Programa Especial de Bachillerato. Lima: Pontificia Universidad Católica del Perú.

CONTRERAS, Carlos (2004). El aprendizaje del capitalismo. Estudios de historia económica y social del Perú Republicano. Lima: IEP.

CUSSIANOVICH VILLARAN, Alejandro (1997). Algunas premisas para la reflexión y prácticas sociales con niños y adolescentes trabajadores. Lima: Radda Barnen.

CUSSIANOVICH VILLARAN, Alejandro (2003). Historia del pensamiento social sobre infancia. Lima: Fondo Editorial de la Facultad de Ciencias Sociales de la UNMSM.

CUSSIANOVICH VILLARAN, Alejandro (2010). Aprender la Condición Humana. Ensayo sobre pedagogía de la ternura. Lima: IFEJANT.

DEGREGORI, Carlos Iván y Pablo SANDOVAL (2009). Antropología y antropólogos en el Perú, la comunidad de ciencias sociales bajo la modernización neoliberal. Lima: IEP-CLACSO.

DELGADO, Eduardo (2004). Aproximación al Pensamiento y Estrategia de la OIT-IPEC para la Erradicación del Trabajo Infantil. En Revista Internacional NATs. Lima: IFEJANT.

FRANCKE, Pedro (2011). ¿Qué desarrollo queremos? En: Diario La Primera. Lima: martes 4 de enero.

FREINET, Celestine (1971). La Escuela Popular Moderna. Lima: Retablos de papel ediciones.

FREIRE, Paulo (1998). Pedagogía de la Autonomía. Saberes necesarios para la práctica educativa. México: Siglo XXI Ediciones.

GOÑI, Niria (2010). Retos y lineamientos para la educación básica regular. En: Rutas hacia un Perú mejor. Qué hacer y cómo lograrlo. Lima-Pontificia Universidad Católica del Perú-CENTRUM.

GENTILE, Pablo (2003). La educación y las razones de la esperanza en una era de desencanto. Lima: IPP.

GUIDDENS, Anthony (2005). Un mundo desbocado. Los efectos de la globalización en nuestras vidas. México: Taurus. 
JARAMILLO GARCIA, Enrique (2003). El trabajo de los Niños, Niñas y Adolescentes pobres y excluidos: Un Derecho Humano Integral, Universal, Indivisible e Irrenunciable. En: Infancia y Adolescencia en América Latina. Aportes desde la Sociología. Tomo II. Lima: Save the Children Suecia, IFEJANT, UNAS, ALAS, Red de Maestrías de Infancia.

JARAMILLO GARCIA, Enrique (2004). Los Maestros en la promoción y defensa de Los Derechos del Niño. Lima: IPP.

JARAMILLO GARCIA, Enrique (2009). La Educación peruana está en el sótano: ¿y como ciudadanos qué hacemos? Lima: Separata.

LAO-MONTES, Agustín (2012). Des/colonialidad del poder, crisis de la civilización occidental capitalista y movimientos antisistémicos. En: Crisis y Movimientos Sociales en nuestra América, Cuerpos, territorios e imaginarios en disputa. DAZA, Mar, HOETMER, Raphael y VARGAS, Virginia (Editores). Lima: Programa Democracia y Transformación Global, Coordinadora Interuniversitaria de Investigación sobre Movimientos Sociales y Cambios Político-Culturales.

LYNCH, Nicolás (2006). Los últimos de la clase. Aliados, adversarios y enemigos de la reforma de la educación en el Perú. Lima: Fondo Editorial de la Facultad de Ciencias Sociales de la UNMSM.

MARIATEGUI, José Carlos (1999). El proceso de la instrucción pública. En: Ensayos sobre Educación Peruana. Lima: Fondo Editorial Universidad Ricardo Palma.

MINISTERIO DE EDUCACION (1970). Informe General de la Reforma de la Educación Peruana. Lima: Ministerio de Educación.

MINISTERIO DE EDUCACION (1993). Indicadores cuantitativos del sistema educativo, Dirección de Estadística, documento de trabajo. Lima: Ministerio de Educación.

MINISTERIO DE EDUCACION (1993). Perú: Calidad, eficiencia, equidad los desafíos de la educación primaria. Lima: Ministerio de Educación.

MONTOYA ROJAS, Rodrigo (2005). Elogio a la antropología. Lima: Instituto Nacional de Cultura-Dirección Regional Cusco, Fondo Editorial de la Facultad de Ciencias Sociales de la UNMSM.

NUGENT, Guillermo (2010). El orden tutelar. Sobre las formas de autoridad en América Latina. Lima: DESCO-CLACSO. 
NUSSBAUM, Martha C. (2010). Sin fines de lucro. Por qué la democracia necesita de las humanidades. Buenos Aires-Argentina: KATZ.

PEIRANO, Luis (2010). Teología y comunicación. Un testimonio sobre Gustavo Gutiérrez. En: Entre la tormenta y la brisa. Homenaje a Gustavo Gutiérrez. Lima: Fondo Editorial de la Pontificia Universidad Católica del Perú-Instituto Bartolomé de las Casas.

PORTOCARRERO, Gonzalo (2010). Los fantasmas del patrón y del siervo como desestabilización de la autoridad legal en la sociedad peruana. En: Cultura política en el Perú. Lima: Red para el desarrollo de las ciencias sociales en el Perú.

RIVERO, José (1999). Educación y exclusión en América Latina, Reformas en tiempos de globalización. Lima: Tarea-Ayuda en acción.

SALAZAR BONDY, Sebastián (2003). Escritos políticos y morales (Perú: 1954-1965). Lima: Fondo Editorial de la Universidad nacional Mayor de San Marcos.

SALAZR BONDY, Augusto (1999). La educación peruana en el mundo contemporáneo. En: Ensayos sobre Educación Peruana. Lima: Fondo Editorial de la Universidad Ricardo Palma.

SANTOS, Boaventura de Sousa (2004). Democratizar la democracia, Los caminos de la democracia participativa. México: Fondo de Cultura Económica.

SANTOS, Boaventura de Sousa (2006). Conocer desde el Sur: Para una cultura política emancipatoria. Lima: Fondo Editorial de la Facultad de Ciencias Sociales de la UNMSM.

SUBCOMANDANTE MARCOS (2002). 7 piezas del rompecabezas mundial. En: Mundo Global ¿Guerra Global? Buenos Aires-Argentina: Ediciones Continente.

SAVATER, Fernando (1998). El valor de educar. Barcelona-España: Ariel.

UGARTECHE, Oscar (1997). El falso dilema. América Latina en la economía global. Venezuela: Fundación Friedrich Ebert-FES (Perú)Nueva Sociedad.

UGARATECHE, Oscar (2010). Para pensar la crisis. En: La crisis mundial y los pobres. Lima: Instituto Bartolomé de las Casas-CEP. 
UGARTECHE, Oscar (2010). Ética y deuda reconsideradas desde el lado de los deudores internacionales. En: Entre la tormenta y la brisa. Homenaje a Gustavo Gutiérrez. Lima: Fondo Editorial de la Pontificia Universidad Católica del Perú. Instituto Bartolomé de las Casas.

VALDEAVELLANO, Rosario (2008). Docencia y contextos multiculturales, Reflexiones y aportes para la formación de docentes desde el enfoque intercultural. Lima: Tarea.

ZEMELMAN, Hugo (2005). De la necesidad de decir lo que decimos: Lo desconocido como nombre. En: Tradición y emancipación en América Latina. CASSIGOLI, Rossana y Jorge TURNER (Coordinadores). México: Siglo XXI Editores.

\section{Notas}

* Educador por la PUCP, Estudios de Maestría Política Social, con mención en Promoción de la Infancia, por la UNMSM, Docente Universitario y Presidente de la Asociación Niños del Río. Las ideas expresadas en el presente trabajo son de mi entere responsabilidad. E-mail: <ejaramillogarcia@hotmail.com>.

${ }^{1}$ GIDDENS, Anthony. Un mundo desbocado

${ }^{2}$ Véase CAPELLA RIERA. Teoría de la Educación

${ }^{3}$ Aparecida, Documento final. p. 82-83.

${ }^{4}$ BOFF, Leonardo. Fundamentalismo, La globalización y el futuro de la humanidad

5 "En lo que se refiera a la crisis ambiental, con la revolución industrial, el vapor irrumpe como fuente de energía y permite la formación de fábricas. En efecto, la relación del hombre con la naturaleza sufrió un cambio a fines del siglo XVIII, cuando decidió que la actividad económica consistía en transformarla. La revolución industrial es un momento fundante del capitalismo." (UGARTECHE, Oscar. Para pensar la crisis. p. 12. En: La crisis mundial y los pobres

6 "Lo evidente es que el planteamiento actual sobre globalización expulsa a la gran parte del mundo y deja solamente a aquellos países con gran capacidad de compra y con alta productividad como parte del sistema global. La globalización es un fenómeno entre países ricos y, para ser más exactos, para los sectores más ricos dentro de los países ricos. Es decir, abre un norte en el mismo norte y un sur en el mismo norte; así como un norte en el sur y un sur en el sur." (UGARTECHE, Oscar (1997). El falso dilema, América Latina en la economía global 7 “[...] la forma hegemónica de la democracia, la democracia representativa elitista, propone extender al resto del mundo el modelo de democracia liberal representativa vigente en las sociedades del hemisferio Norte, ignorando las experiencias y las discusiones oriundas de los países del Sur en el debate 
sobre la democracia." (SANTOS, Boaventura de Sousa (2004). Democratizar la democracia.

8 "El sistema escolar actúa a la manera del demonCapital Cultural, Escuela y Espacio Social

9 "La geografía peruana se caracteriza, entonces, por la heterogeneidad de los ecosistemas y la correspondiente biodiversidad, contribuyendo a la gran diferenciación económica, social y cultural. Es importante reconocer que nuestro país ocupa el $0.7 \%$ de la superficie de la tierra y sin embargo tiene 84 de las 104 zonas de vida que existen en el mundo y 28 de los 32 tipos de clima. Es uno de los cinco países con mayor diversidad biológica y uno de los mayores centros de germoplasma de especies domésticas de flora y fauna del mundo. Se conocen cerca de 1,200 especies silvestres de plantas útiles para diversos fines. Por lo tanto, lo que define al Perú es la gran diversidad ecológica y biológica concentrada en un pequeño espacio geográfico." (Plataforma de Contrapartes de Novib en el Perú. Construyamos ciudadanía y un hábitat más humano. p. 18).

${ }^{10}$ Véase MARIÁTEGUI, José Carlos. El proceso de instrucción pública. p. 98104. En: Ensayos sobre Educación Peruana

11 "En estos doscientos años la transformación de la naturaleza se volvió depredación, sobre la que encima se agregaron los contaminantes derivados de los energéticos. Y lo hemos hecho con tanto éxito que, si seguimos a este paso, en cien años tendremos el fin del planeta como lo conocemos, porque sobre el patrón de producción y consumo energético anterior no hay vida posible en un futuro previsible. Por eso tenemos que cambiar nuevamente la relación del hombre con la naturaleza" (UGARTECHE, Oscar. Op. Cit. p. 12).

${ }^{12}$ Véase MARIÁTEGUI, José Carlos. Op. Cit. p. 98-104.

13 "Tenemos ciudadanos que no han dejado de ser siervos y representantes que aún son patrones. $\mathrm{Y}$ ambos se inculpan mutuamente. Los ciudadanos (siervos) explican su incredulidad frente a la ley como una reacción en contra de autoridades que son, en realidad, patrones encubiertos, gente corrupta que solo busca su propio beneficio. Y, de otro lado, las autoridades (patrones) piensan que los continuos desacatos frente a la ley provienen de la ignorancia de una mayoría acicateada por los que quieren desestabilizar la democracia". (PORTOCARRERO, Gonzalo. Los fantasmas del patrón y del siervo como desestabilizadores de la autoridad legal en la sociedad peruana. p.13-14. En: Cultura política en el Perú

${ }^{14}$ Ibíd. Mariátegui, José Carlos.

${ }^{15}$ Véase LAO-MONTES, Agustín. Op. Cit. p. 81.

${ }^{16}$ Véase CAPELLA RIERA, Jorge. Política Educativa

${ }^{17}$ Ibíd. p. 222.

${ }^{18}$ Véase VALDEAVEllanO, Rosario. Presentación. p. 8. En: Docencia y contextos multiculturales, reflexiones y aportes para la formación de docentes desde el enfoque intercultural

19 "Pues bien, la educación es tarea de sujetos y su meta es también formar sujetos, no objetos ni mecanismos de precisión: de ahí que venga sellada por 
un fuerte componente histórico-subjetivo, tanto en quien la imparte como es quien la recibe". (SAVATER, Fernando. El valor de educar

${ }^{20}$ Véase RIVERO, José. Educación y exclusión en América Latina, Reformas en tiempo de globalización

${ }^{21}$ Véase FREIRE, Paulo. Pedagogía de la Autonomía

${ }^{22}$ Cuando se dice lo político se debe señalar la esfera del ejercicio del patrón del poder del Estado donde se toman o dejan de tomar, de acuerdo con una determinada relación de fuerzas, las decisiones que afectan a la sociedad.

${ }^{23}$ Véase LYNCH, Nicolás. Los últimos de la clase

${ }^{24}$ Ibíd. p. 23

${ }^{25}$ LYNCH, Nicolás. Op. Cit. p. 35-47

${ }^{26}$ Véase JARAMILLO GARCÍA, Enrique (2004). Los Maestros en la promoción $y$ defensa de Los Derechos del Niño

27 "Con esto quiero decir que nuestra educación debe ser ahora, no puede ser ahora sino una educación de la crisis. Lo cual implica un cambio completo de actitud en los planteamientos educativos respecto de posiciones del pasado. [...]. Es preciso cambiar esta perspectiva: no debemos buscar una educación que ignore la situación real del país o que la evite, ni una educación que, por sus propias virtudes y construyéndose sin soporte real, pueda salvar al país, sino que la educación que nuestra comunidad necesita y sea capaz de construir en estos momentos". (SALAZAR BONDY, Augusto. La Educación Peruana en el mundo contemporáneo. p. 174-175. En: Ensayos sobre Educación Peruana

${ }^{28}$ SALAZAR BONDY, Augusto. Op. Cit. p. 175.I

29 “[...], podemos reafirmar, por una parte, que tanto las ONGs de desarrollo como los organismos internacionales ligados a la ONU (OIT, UNICEF; y BANCO MUNDIAL) han tenido la habilidad de abrir el camino para que transite el modelo económico neoliberal, en tanto sus políticas, lejos de cuestionarlo, han servido más bien, para amortiguar sus impactos, profundizar la reasignación en sus beneficiarios y tranquilizar la "mala conciencia" del modelo empobrecedor." (DELGADO, Eduardo. Aproximación al Pensamiento y Estrategia de la OIT-IPEC para la Erradicación del Trabajo Infantil. p. 75. En: Revista Internacional NATS $N^{\circ} 11-12$

${ }^{30}$ BOFF, Leonardo. Op. Cit. Pág. 34.

${ }^{31}$ BOFF, Leonardo. Op. Cit. Pág. 34.

${ }^{32}$ Véase Nussbaum, Martha C. Sin fines de lucro. Por qué la democracia necesita de las humanidades. Pág.28.

33 "Creer en el Dios de la Vida es también creer en el poder de la imaginación y la capacidad de creación artística, volcarse a la esperanza de una salvación que no es otra cosa que vivir en el sentido más pleno que puede tener la vida." (PEIRANO, Luis. En: Entre la tormenta y la brisa

${ }^{34}$ Véase JARAMILlO GARCÍA, Enrique. El Trabajo de los Niños, Niñas Y Adolescentes Pobres y excluidos: Un Derecho Humano, Integral, Universal, Indivisible e Irrenunciable. p. 255-267. En: Infancia y Adolescencia en América Latina 
${ }^{34}$ VALDEAVELLANO, Rocío. Op. Cit. p. 10.

35 "No hay que olvidar que si un niño trabaja y se le impide el trabajo -tal como lo hacen los encallecidos dueños de establecimientos públicos- no se hace otra cosa que empujarlo al delito, pues el rechazo de lo que es lícito equivale a una mala lección cuyas consecuencias en un alma tierna pueden ser con los años socialmente trágicos". (SALAZAR BONDY, Sebastián. Escritos políticos y morales (Perú: 1954-1965). p. 54.

${ }^{36}$ Véase CONTRERAS, Carlos. El aprendizaje del capitalismo

37 Véase DEGREGORI, Carlos Iván y Pablo Sandoval. Antropología y la antropología en el Perú, la modernidad de las ciencias sociales bajo la modernización neoliberal

${ }^{38}$ Véase FREINET, Celestine La Escuela Popular Moderna. p. 24.

39 "La valoración crítica del trabajo es una exigencia del derecho a no ser excluido social, cultural y políticamente. La ciudadanía supone la valoración también de la contribución social como trabajador. Se podría argüir que reconocer el valor del trabajo como derecho de la persona no cambia en nada las actuales condiciones en la las que los NAT viven, y esto es desgraciadamente cierto. Pero también es cierto que se trata de una visión que no toma en cuenta otras dimensiones y presupone asignarle al derecho un papel mágico en la transformación de la realidad, negándole al mismo tiempo, más allá de esta limitación, su papel como portador de valores, de un mensaje ético, de una fuerza cultural, de un contenido filosófico y simbólico, de un elanAlgunas premisas para la reflexión y las prácticas sociales con niños y adolescentes trabajadores

${ }^{40}$ Según prestigiosos economistas, como Félix Jiménez, profesor de Economía en la PUCP, con la aplicación de las reformas neoliberales al compás de la música celestial del Consenso de Washington, se inicia un proceso de mercantilización y privatización de la educación, la salud y otros derechos como el trabajo. Desde entonces y hasta la fecha no ha sido posible el ejercicio pleno del derecho a una educación de calidad y el ejercicio pleno de los derechos conquistados en otros aspectos como el derecho a la salud y a un trabajo digno. Aumentó la desigualdad, pobreza, marginalidad y exclusión, disminuyó notablemente la participación de los salarios en el ingreso nacional, en suma, desaparecieron lamentablemente las bases materiales para el ejercicio protagónico de la ciudadanía. Los ciudadanos se hicieron menos reales, debido a que las conquistas importantes - como el derecho a la educación de calidad, la salud, el trabajo digno, la propiedad de la tierra, que surgieron como un derecho social y no civil -, perdieron total relevancia e importancia. Esta regresión o retroceso en el tiempo y la historia empezó a convivir con el ejercicio mediatizado de la democracia.

${ }^{41}$ La Convención sobre los Derechos del Niño constituye indudablemente la más clara, extensa y profunda ruptura ideológica de un orden tutelar autoritario y excluyente, aquel que propugnaba la Doctrina de la Situación Irregular. La Convención no obstante su aire occidental y monocultural ha sido definida frecuentemente como una verdadera revolución, que transforma al "menor en ciudadano", 
${ }^{42}$ Después de 21 años de aplicación de neoliberalismo "a la peruana", actualmente en todos los campos de la vida social en la sociedad peruana existe una burda estratificación social. Los estratos A y B viven en la opulencia y el boato; y los estratos C, D y E, sobreviven en la miseria y desesperanza.

43 "En la década de los noventa, los agentes económicos compran empresas quebradas o empresas públicas, que no son sinónimos, antes que poner nueva inversión y ampliar la formación bruta de capital. Esta viene con el discurso de la privatización y eficiencia." (UGARTECHE, Oscar. Op. Cit. p. 21).

${ }_{44}$ "Una reflexión sobre las posibilidades de la educación en el país, enfrenta, por lo común, dos tipos de obstáculos: por una parte, la educación está cada vez más segregada socialmente; y, por otra, los intelectuales más exitosos suelen despotricar contra el Perú en diversas formas y estilos, dando lugar al pesimismo cultural. Esencialmente, este discurso sostiene que el Perú no es un lugar para vivir con decencia y que lo mejor que puede hacerse es migrar." (NUGENT, Guillermo. El orden tutelar. Sobre las formas de autoridad en América Latina. p. 37).

${ }^{45}$ Véase JARAMILLO GARCÍA, Enrique. La Educación peruana está en el sótano

46 "En el modelo de la reforma de los años 70, el sistema educativo comprendía tres niveles: Educación inicial para niños de 0 a 5 años, educación básica que comprendía tres ciclos con un total de nueve grados (4 grados el primer ciclo; 2 el segundo ciclo y 3 el tercer ciclo) con las modalidades Básica, Laboral, Especial y Calificación Profesional Extraordinaria; Educación Superior con tres ciclos ${ }^{47}$ Véase ARANA CARDÓ, José. Los caminos de la Gestión en la escuela Pública ${ }^{48}$ Entre 1980 y 1990, el porcentaje de docentes sin título pedagógico en el sector público pasó del 19,37\% al 50,60\% MED. Dirección de Estadística 1993. Indicadores cuantitativos del sistema educativo (documento de trabajo).

49 MED. 1993, Perú: Calidad, eficiencia, equidad los desafíos de la educación primaria. p. 68.

50 "Vivimos tiempos de exclusión y de guerra. Tiempos donde la violencia y la segregación se apoderan de la vida de millones de personas. Vivimos en un mundo, donde el propio mundo, parece ser un privilegio de aquellos que pueden pagar (y caro) por el espacio que ocupa en él. Vivimos tiempos de desencanto y desilusión. Tiempos sin espacio para la esperanza. Tiempos donde hablar de lo posible acabó tomándose una excusa para que lo imposible alimente sueños, inspire luchas, construya proyectos, edifique utopías." (GENTILE, Pablo. La educación y las razones de la esperanza en una era de desencanto. p. 15. En: Políticas de formación docente y lucha contra la pobreza

${ }^{51}$ GENTILE, Pablo. Op. Cit. p. 15.

${ }^{52}$ La corrupción virtualmente arranca de la boca de los pobres los recursos económicos que deberían servir para aliviar sus padecimientos, para invertir en salud y educación. Combatirla radicalmente es una de las tareas que deberíamos fijarnos para hacer del Perú un hábitat más humano y vivible.

${ }^{53}$ GENTILE, Pablo. Ibíd. p. 15-16. 
${ }^{54}$ LYNCH, Nicolás. Op. Cit. p. 68-69.

${ }^{55}$ Diez años después de las ilusiones de transición democrática fallida, y una prosperidad falaz con las que entró al siglo XXI, el Perú del 2011 enfrenta graves conflictos sociales, crisis de la educación y exigencias de inclusión, vive la ruleta de los precios de los minerales, el gas y otros productos que exporta y enfrenta el riesgo de que se sigan imponiendo los políticos que no desean cambios. Es por ello, cuando escuchamos decir que nuestra economía va bien y hay una revolución silenciosa en la educación, y que sólo nos falta distribuir mejor, que nadie nos para y estamos cerca a llegar a ser del "primer mundo", no podemos dejar de sentir que nos están tomando el pelo e insultando a nuestra inteligencia. ${ }^{56}$ Véase FRANCKE, Pedro. ¿Qué desarrollo queremos? p. 10. En: Diario La Primera

${ }^{57}$ Véase GARCÍA LLORENS, Mariel. El discurso del perro del hortelano y las articulaciones actuales entre la política y medios de comunicación en el Perú. p. 136. En: Cultura política en el Perú

${ }^{58}$ GENTILE, Pablo. Op. Cit. p. 16.

${ }^{59}$ Véase GOÑI, Niria. Retos y lineamientos para la Educación Básica Regular. p. 304-305. En: Rutas hacia un Perú mejor

${ }^{60}$ Véase Acuerdo Nacional. Políticas de Estado. p. 31-32

${ }^{61}$ GOÑI, Niria. Ibíd. p. 304-305.

62 Véase BALBI Scarneo, Carmen Rosa y Carlos Arámbulo Quiroz. La recomposición de las clases medias y el voto en el Perú. p. 299. En: Cambios Sociales en el Perú 1968-2008

63 "Pasaron 200 años y el Perú y casi toda América Latina sigue exportando piedras y materias primas, casi las mismas que exportábamos a finales del siglo XVIII: cobre, plata, zinc, café, azúcar, cacao, etc. Y ahora petróleo, gas y recursos forestales." (UGARTECHE, Oscar. Para pensar la crisis. p. 12. En: La crisis mundial y los pobres. Los agregados $Y$ ahora petróleo, gas y recursos forestales son míos

${ }^{64}$ MONTOYA ROJAS, Rodrigo. Op. Cit. p. 19.

${ }_{65}$ "La globalización es una palabra que incluye diversos conceptos: desde la generalización al acceso a la información hasta la integración de los mercados de bienes, servicios, capitales y trabajo. Se considera que la globalización de las economías será lo que permitirá el desarrollo. En la globalización la competencia se hace por productividad." (UGARTECHE, Oscar. Op. Cit. p. 114).

${ }_{66}$ "En nuestro país, 1 de cada 3 niños, niñas y adolescentes entre 6 a 17 años trabaja. [...] Durante los últimos años la tendencia del trabajo infantil y adolescente ha sido constante entre 1993 y el 2001 el trabajo infantil de menores de edad se ha triplicado y no existe ningún indicador que sugiera la reversión de esta tendencia. Siguiendo estimaciones del Instituto de Estadística e Informática (INEI), para el año 2005, la tasa de participación laboral de la población de 6 a 17 años alcanzaría el 32\%. En términos absolutos, esto quiere decir que para el 2005 el volumen total de niños, niñas y adolescentes trabajadores entre 6 y 17 años alcanzaría la abrumadora cifra de 2 millones 265 mil menores de edad." 
Plan Nacional de Prevención y Erradicación del Trabajo Infantil 2005-2010. p.13. Ministerio de Trabajo y Promoción del Empleo.

${ }^{67}$ Véase Sub Comandante Marcos. 7 piezas del rompecabezas mundial. p. 74. En: Mundo Global ¿Guerra Global?

68 "El primer teórico en introducir la noción de competitividad fue David Ricardo, cuando definió las ventajas comparadas que podría tener una economía para producir un bien sobre los que tendría otra economía para producir el mismo bien. Se puede resumir este concepto como la adecuación de recursos humanos, materias primas disponibles y medios de producción para manufactura al menor costo posible, de un bien exportable que ningún otro puede manufacturar a ese costo" (UGARTECHE, Oscar. Ibíd. p. 87).

${ }^{69}$ Véase NUSSBAUM, Martha C. Sin fines de lucro

${ }^{70}$ Ibíd. p. 41-42.

${ }^{71}$ Tomado de Gustavo Gutiérrez: "Esa irrupción es la fuente de una espiritualidad, de un caminar colectivo - o comunitario si se prefiere - hacia Dios".

72 "Como dice Gustavo Gutiérrez, "la pobreza en última instancia significa muerte, carencia de alimento y de techo, imposibilidad de atender debidamente a necesidades de salud y educación, explotación del trabajo, desempleo permanente, falta de respeto a la dignidad humana e injustas limitaciones a la libertad personal en los campos de expresión, lo político y lo religioso, sufrimiento diario". Esta condición se vio acentuada por una inequidad en el sistema internacional y por una profunda injusticia en la forma como el poder manejó los problemas de la economía global que deben ser resaltados". (UGARTECHE, Oscar. Ética y deuda reconsideradas desde el lado de los deudores internacionales. p. 184. En: Entre la tormenta y la brisa

${ }^{73}$ NUSSBAUM, Martha C. Op. Cit. p. 4749.

${ }^{74}$ Véase LERNER FEBRES, Salomón. Educación, memoria y derechos humanos. p. 160-161. En: Entre la tormenta y la brisa

${ }^{75}$ NUSSBAUM, Martha C. Op. Cit. p. 87-94.

${ }^{76}$ CEPELLA RIERA, Jorge. Op. Cit. p. 223-224.

${ }^{77}$ Ibíd. p. 233.

${ }^{78}$ El subtitulo lo he tomado del libro La Escuela Popular Moderna, de Celestine Freinet.

79 "Una pedagogía de la ternura o es sustantivamente una pedagogía crítica o deja de ser histórica hacia atrás, en el hoy y hacia adelante. [...]. La pedagogía de la ternura en cuanto pedagogía crítica está llamada a hacer del malestar, la indignación y el inconformismo frente a lo que existe, una fuente de inspiración para teorizar sobre el modo de superar el estado de cosas y muy en particular en cómo hacer que los seres humanos no terminen naturalizando la situación, autoinculpándose o simplemente tornándose pasivos y aguantadores". (CUSSIÁNOVICH VILLARÁN. Alejandro. Aprender la Condición Humana. Ensayos sobre pedagogía de la ternura. p. 23).

${ }^{80}$ Véase FREINET, Celestine. La escuela Popular Moderna

${ }^{81}$ CAPELLA RIERA, Jorge. Op. Cit. p. 230. 
82 “[...] La participación es deudora de un proyecto social, que se concreta en que cada uno llegue a ser lo que es: sujeto y no objeto; sujeto con dignidad. El protagonismo es la teoría de la práctica participativa. [...]. La 'participación protagónica' no es un mero ejercicio pedagógico, simbólico. Es un derecho en que se juega la dignidad de los pueblos y de los individuos." (CUSSIÁNOVICH VILLARÁN, Alejandro. Historia del pensamiento social sobre infancia . p. 28 y30).

83 "Este modelo de globalización tiene el peligro de bifurcar la familia humana: por un lado, un pequeño grupo de naciones opulentas metidas hasta las cejas en el consumo material, con una espantosa pobreza espiritual y humana, y poniendo todos los beneficios de la tecnociencia a su propio servicio; por otro lado, las multitudes barbarizadas y abandonadas a su propia suerte, convertidas en combustible para hacer funcionar la máquina productivista, condenadas a morir antes de tiempo, víctimas del hambre crónica, de las enfermedades de los pobres y de la degradación general de la Tierra. Tenemos, pues, mil razones para oponernos a este tipo de globalización, que no puede perpetuarse al precio de comprometer el futuro de la especie humana." (BOFF, Leonardo. Virtudes para otro mundo posible. I Hospitalidad: derecho y deber de todos. p. 52).

${ }^{84}$ " [...] trabajar es un valor en sí mismo, es una actividad noble y jerarquizadora... hay que seguir trabajando aunque no se vea qué cosa no se tenga podrá aportarnos el trabajo; y aunque eso no lo necesitemos para nada. Trabajar es bueno; no hacerlo es malo. [...]. El trabajo es el estado normal de los seres humanos; no trabajar es anormal." (BAUMAN, Zygmunt. Trabajo, consumismo y nuevos pobres. p.17-18)

${ }^{85}$ CUSSIÁNOVICH VILLARÁN, Alejandro. Op. Cit. p. 16. 
